Supporting information for

\title{
Dual-Degradable Biohybrid Microgels by Direct Crosslinking of Chitosan and Dextran using Azide-Alkyne Cycloaddition
}

Helin $\mathrm{Li}^{\#}$, Xin Li ${ }^{\#}$, Puja Jain, Huan Peng, Khosrow Rahimi, Smriti Singh and Andrij Pich*

KEYWORDS: chitosan, dextran, click chemistry, dual-triggered degradation, drug release 


\section{Experimental Section}

Synthesis of azide modified dextran (dextran-azidopropylcarbonate)
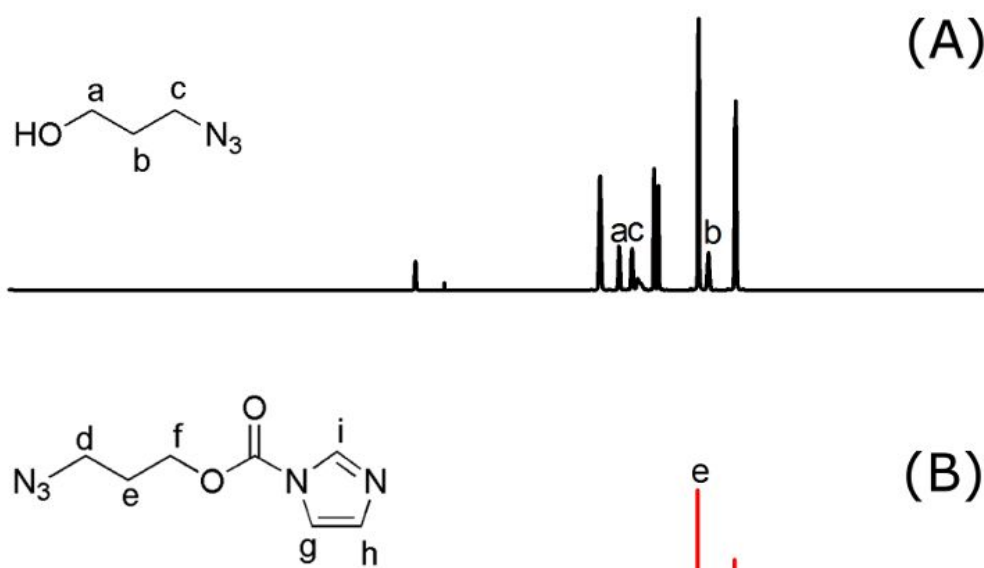

(B)
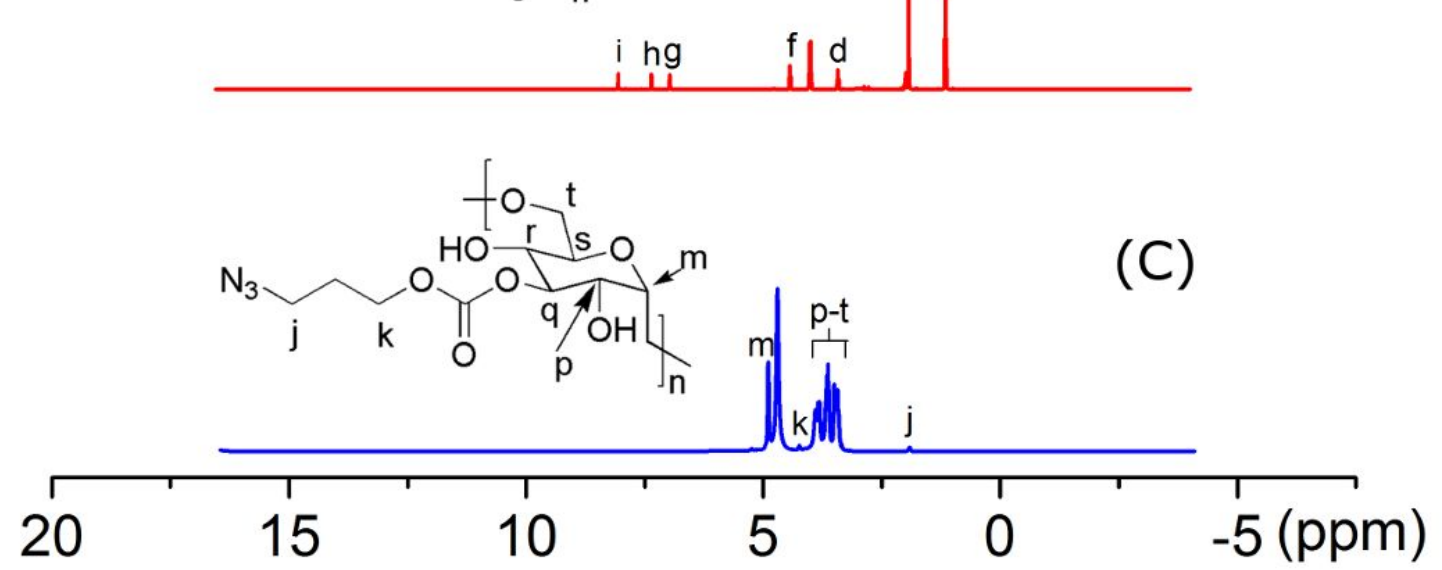

Figure S1. ${ }^{1} \mathrm{H}$ NMR spectra for three steps of azide modified dextran (dextranazidopropylcarbonate) synthesis, exhibiting the 1-azido-3-propanol (A), the 3azidopropyl carbonylimidazole (B) and the dextran-azidopropylcarbonate (C) in $\mathrm{CDCl}_{3}$.

Synthesis of alkynyl modified chitosan (alkynyl-pendant chitosan) 

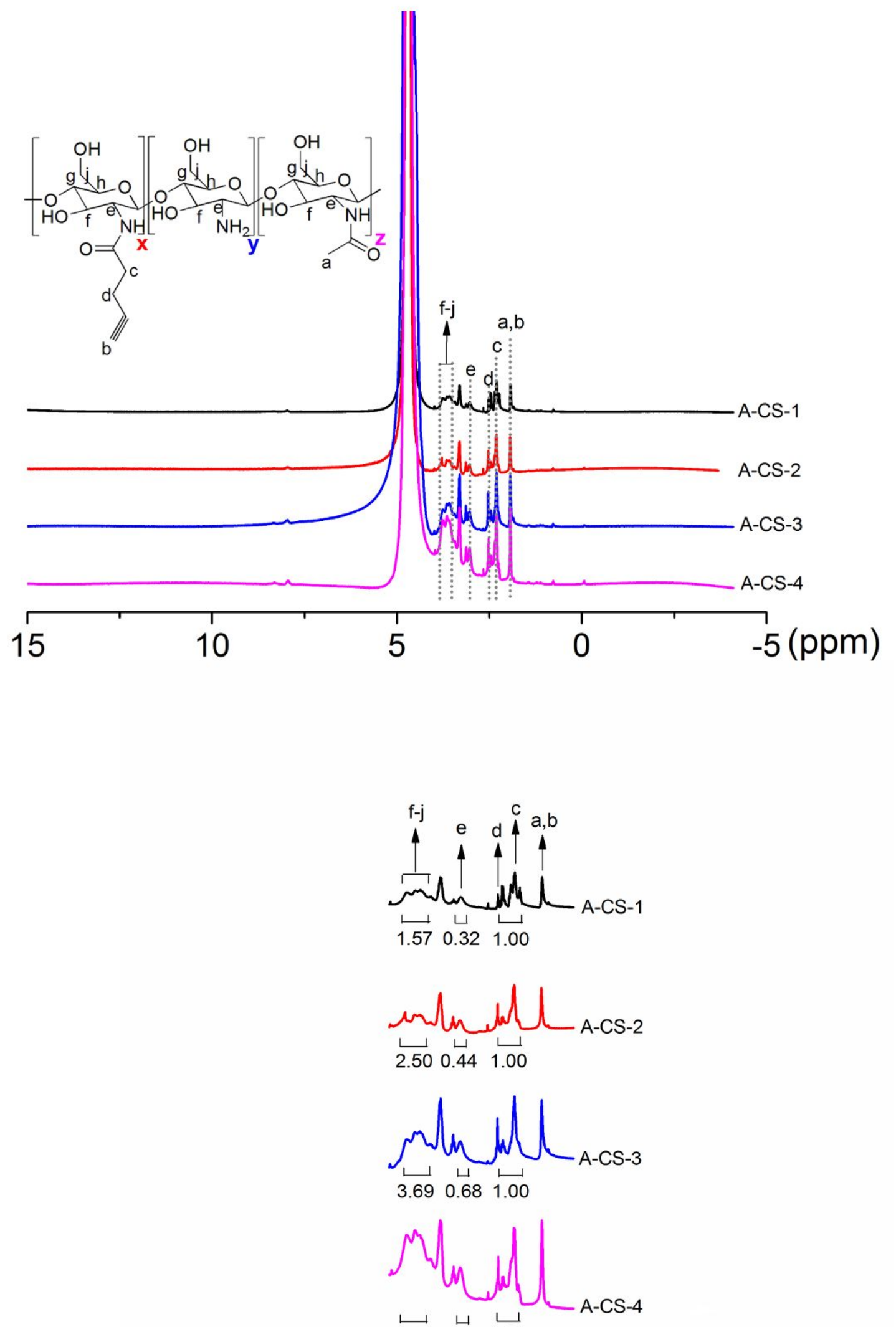

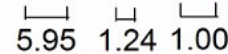

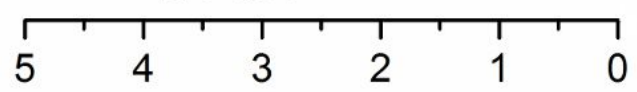


Figure S2. ${ }^{1} \mathrm{H}$ NMR spectra and enlarged ${ }^{1} \mathrm{H}$ NMR spectra from 1.5 to $4 \mathrm{ppm}$ for four types of alkynyl modified chitosan (alkynyl-pendant chitosan) synthesis in $\mathrm{D}_{2} \mathrm{O} / \mathrm{DCl}$.

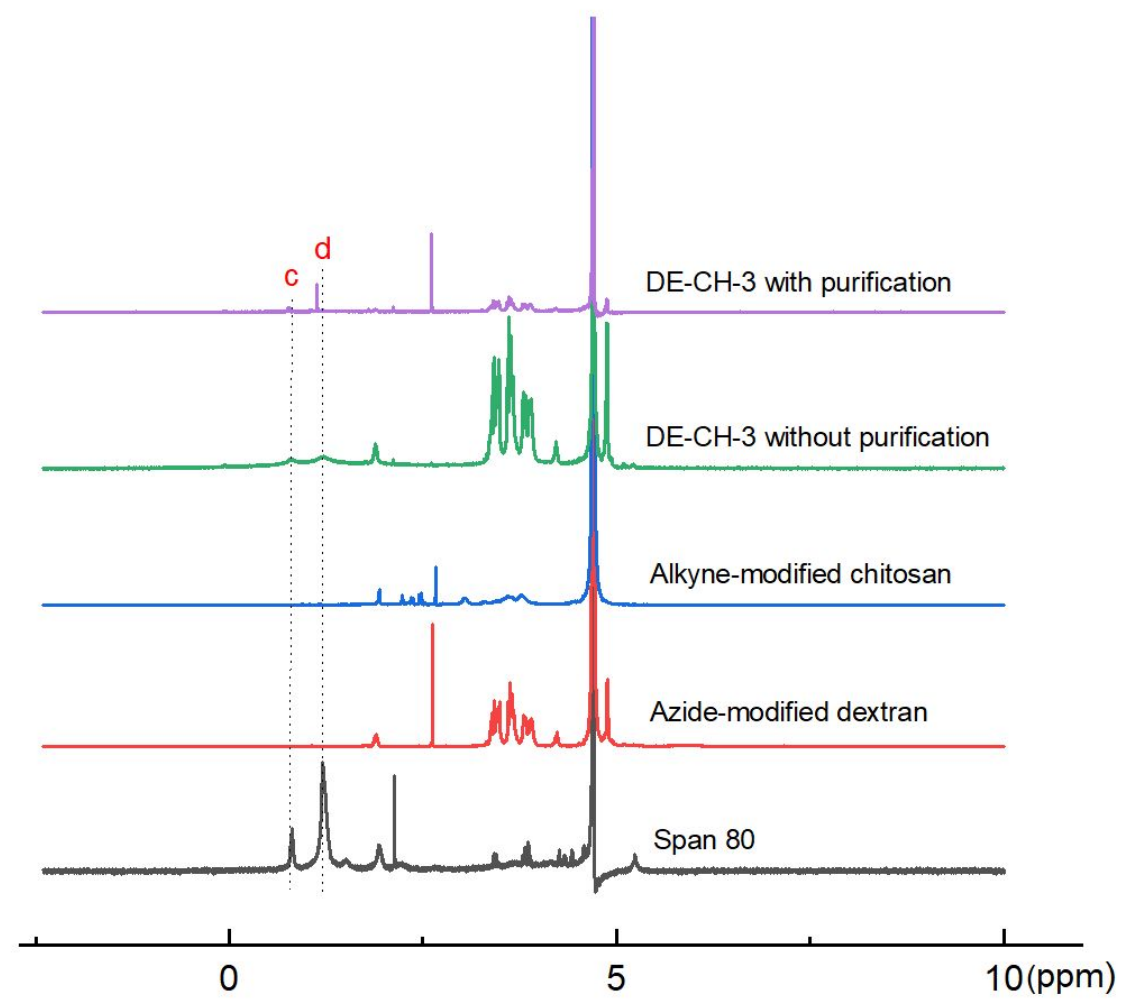

Figure S3. ${ }^{1} \mathrm{H}$ NMR spectra for Span 80, two prepolymers (modified chitosan or dextran), DE-CH-3 microgel with/without purification in $\mathrm{D}_{2} \mathrm{O}$. 
(A)

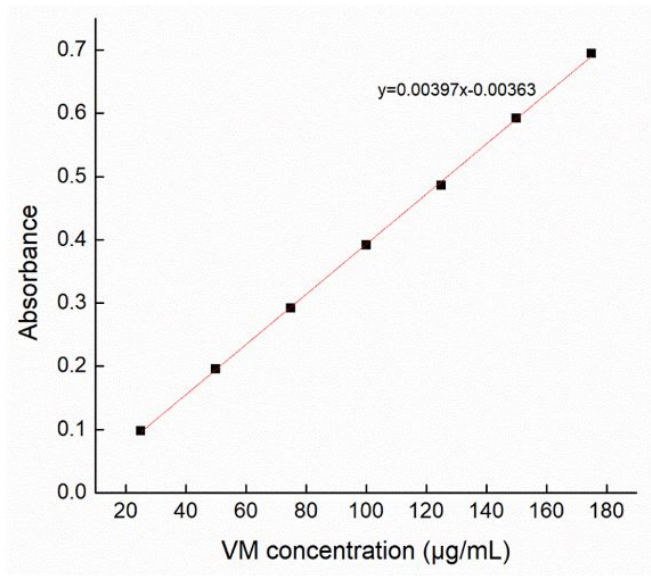

(B)

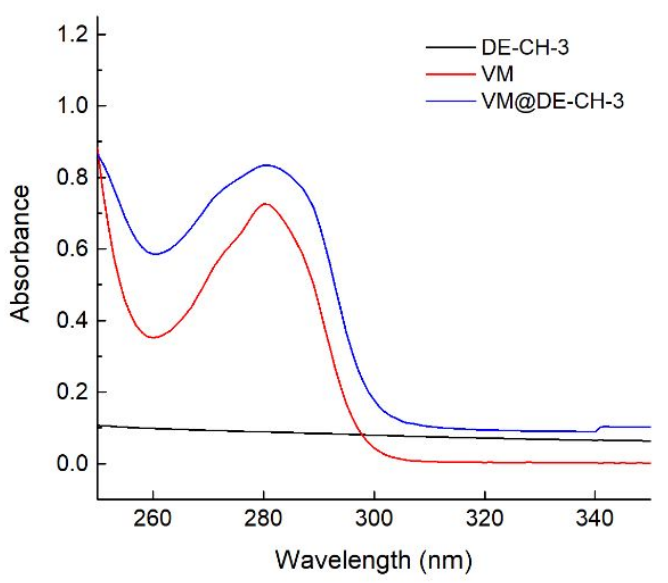

Figure S4. The standard calibration curve of VM (A), and UV-Vis spectra of DE-CH3 microgel, vancomycin hydrochloride (VM) and VM-loaded DE-CH-3 microgel (VM@DE-CH-3) (B).

Table S1. Degree of substitution of alkyne groups in modified chitosan in this work (determined by ${ }^{1} \mathrm{H}$ NMR) (Figure S2) and the integrated areas under the peaks were measured by MestRec NMR software.

\begin{tabular}{ccccc}
\hline & Chitosan(g) & $\begin{array}{l}\text { 4-pentynoic } \\
\text { acid (g) }\end{array}$ & $\begin{array}{l}\text {-C } \equiv \mathrm{C} \text { in 4-penty-noic } \\
\text { acid (mmol) }\end{array}$ & $\begin{array}{c}\text { DS of -C } \equiv \mathrm{C} \\
(\mathrm{mol} \%)\end{array}$ \\
\hline Alkynyl-CH-1 & 0.1 & 0.0536 & 0.546 & 78 \\
Alkynyl-CH-2 & 0.1 & 0.0366 & 0.3723 & 57 \\
Alkynyl-CH-3 & 0.1 & 0.0244 & 0.2482 & 37 \\
Alkynyl-CH-4 & 0.1 & 0.0122 & 0.1241 & 20 \\
\hline
\end{tabular}

